\title{
The Development of Educational Games Supported by a Pedagogical Tutor Agent
}

\author{
Franciele da Silva Lewandowski and Adriana Soares Pereira \\ Centro Universitário Franciscano - UNIFRA, Brazil \\ fran.lewski@gmail.com, apereira@unifra.br
}

\begin{abstract}
New technologies of information provide facilities for the didactic means of education. This article presents the development of two educational games supported by agents that help students during their interaction with the games. The proposed agent is based on a pedagogical concept that seeks to respect students' individual development and learning. The educational games are: "Password Game", which stimulates logic reasoning; and "Math Space", which helps the basic learning of mathematics. They were developed in Flash programming, and were aimed at children from the first to the third years of Elementary School.
\end{abstract}

Keywords: Games, Tutor, Multimedia, Elementary School.

\section{Introduction}

The use of computers in education has fostered great changes through the development of Information and Communication Technologies (ICTs) in teaching and learning methodologies. This has occurred due to the widespread of information technologies in people's lives, which has caused transformations both in society and in teaching conditions.

Several studies and papers have been developed to show the efficacy of the use of information technology in teaching. Here we mention an article [1] that presents the importance of educational games for fostering motivation in students' learning, a paper [2] that shows the use of games to make learning more pleasant and interesting and a research [3] that presents the development of a pedagogical agent in Intelligent Tutoring Systems.

According to the Multiple Intelligences Theory [4], which considers intellectual capacity as a set of abilities whose learning are independent from one another, people are not given the same set of abilities, but each person can develop all intelligences naturally. Individuals can continue to develop any type of intelligence as long as they practice them and face challenges, reflecting upon what is learned. By using games, learners explore information around them and improve their mental capacity, developing and enriching their personality [5].

The objective of this study is to develop educational software in the form of games that help teachers to give their lessons using available computer technology. The games should cater to the objective of curricular activities, so as to guarantee individuals' 
formation and to motivate them for the new technological reality. The games should also be founded on a certain pedagogical structure, using reactive pedagogical agents which guide students' interaction and stimulus.

This article shows the development of the game called 'Password', which stimulates learners' logic reasoning. The game can be played either in pairs or with the computer. The other game whose development is presented in this article is 'Math Space', which explores the contents of basic mathematics, aiming at a more pleasant learning experience. The characters 'Dr. Burns' and 'Nani' are the agents that monitor students in their interaction with the activities, helping them in the task of learning by pointing out and suggesting alternatives, complimenting and helping students to understand the game.

The article is organized in seven sections. Section 2 gives a general view of the educational software; Section 3 briefly describes the pedagogical agents; Section 4 presents the environment that was developed; Section 5 shows the characteristics and the development of the agent; Section 6 offers the obtained results; and Section 7 presents the final considerations.

\section{Pedagogical Agent}

Artificial Intelligence (AI) is defined as the study in computer science that enables the development of perceiving, reasoning and acting [6]. In Education, AI is considered nowadays as a new methodology for improving knowledge.

In this artificial case, the agents are entities, and they can be defined as any entity (human or artificial) that is immersed or placed in an environment, perceives it through sensors and acts on it by means of actors. Agents act upon their own implicit or explicit objectives and, in order to achieve them, select their actions due to their perceptions.

The agents that perform an educational or pedagogical function that facilitates or improves student learning are called pedagogical agents. They can present characteristics of reactive agents, as they respond to changes in the environments where they are used.

According to [7], they can be classified as:

- Tutors: those that are aimed at students' directed teaching;

- Assistants (Friends): those that cooperate with students' learning;

- Web Agents: those that aim at employ the Internet to teaching;

- Mixed Agents: those that teach and learn.

The use of pedagogical agents in teaching becomes fundamentally important as they provide interactive and dynamic feedback between the environment and the student, and make the communication more persuasive, as they perform the role of a guide to the user.

According to [7], the introduction of agents in educational softwares allow for essential improvement in the pedagogical aspects of learning environments, once they provide more intense interactions as students approach the game. 


\section{Developed Environment}

For the development of the educational games reported here the following technologies were used: JUDE Professional for UML modeling of the activities diagram with parallel behavior and Adobe Flash CS3, which is widely used in the development of educational games due to its flexibility, because it is an excellent authorship tool, because it has the ideal pedagogical character, and it offers resources and functionalities that developers need.

ActionScript Language was chosen for its resources and functionalities and because it is a consistent programming language aimed at objects.

The methodology used in the teaching-learning project through games is based on the performance of practical activities intended to improve curriculum activities, which brings teaching beyond the conventional classroom method.

\subsection{Methodology}

The need to think about a theme and define the objectives to be achieved allows for the adequate development of educational games.

To plan and model the environment, along with the proposed agent, a questionnaire with ten multiple-choice question and one dissertative question was designed and sent to four schools. The questionnaire was answered by fourteen Elementary School teachers. Some of the questions in the questionnaire were: How much do you know about computers? What teaching resources does the school have? Is there a frequently used computer lab in the school? Do you use computer resources to plan classes? Do you plan computer-based activities? In which area should emphasis be placed when computer resources are used? In which grades of Elementary School should computer-based activities be used?

The schools that participated in the research were:

- Escola Estadual de Ensino Médio Lilia Guimarães, in Uruguaiana, Rio Grande do Sul.

- Escola Nossa Senhora do Horto, in Uruguaiana, Rio Grande do Sul.

- Instituto Laura Vicuña, in Uruguaiana, Rio Grande do Sul.

- Escola Municipal de Educação Fundamental Centro de Atenção Integral à Criança Luizinho De Grandi, in Santa Maria, Rio Grande do Sul.

From the answers obtained in the fourteen questionnaires, graphs were produced to determine the profile of the games. The answers showed that the areas in Elementary School where the employment of computer resources was needed the most were mathematics (mentioned in $73.33 \%$ of the answers) and logic (mentioned in $86.66 \%$ of the answers). The games and their respective agents were created to cater to the target-audience and their needs. The activities for the games were selected with the aid of the teachers who participated in the research.

The use of the game was made possible because all schools have a laboratory with computers, and most teachers have knowledge of computers and use different methods for planning and performing classroom activities. 


\subsection{Properties of the Games Environment}

One important effect of using computers in Education is the development of environments that foster learning. However, the creation of an environment that supports the learning process and that makes use of ICT needs applied planning.

The agents act with their "solutions" within task environment. But it is important to notice that the kind of environment directly affects the project that is adequate to the agent's program [8]. During the first phase of the planning of an agent, all the aspects of the task environment must be individualized. These aspects define the appropriate project for the agent and its applicability.

In the acting of the developed agent, the environment must be accessible, that is, completely observable. The agent's sensors must have access to the complete state of the environment, so as to detect essential aspects for the selection of its action. The agent is, thus, capable of knowing what action was performed by the student. The environment must also be episodic. Each activity (episode) that the student performs is based on the agent's perception and action, and the chosen course of action depends only on the episode itself.

The agent's task environment is considered small due to the number of perceptions and performed actions.

\section{3 "Password Game"}

"Password Game", one of the games developed in this study, is the development of a computer-based version of an already existing board form of the game. The game stimulates students' logic reasoning, which is important in helping students to think critically about the contents of all disciplines. The objective of the game is to discover a created or generated password in up to twelve attempts, following a checking chart of correct colors in correct places or correct colors in wrong places, with the agent's aid. In this game, there can be repetition of colors, and the student must think of all possibilities.

Figure 1 presents the initial screen of "Password". It is possible to create a password for another player to discover. This is done by clicking on the desired sequence of color buttons (yellow, blue, green and red). It is also possible to ask the program to generate a password. This is done by clicking on the "Generate Password" button. The student can also ask the program for help. In this case, the student clicks on the "Instructions" button to see the agent's explanation.

Figure 2 shows the game steps screen. In this screen, the student attempts to discover the password by clicking on the desired color sequence. In the checking table the markers indicate whether or not the student correctly guessed the colors and their order. The black ball indicates the correct color in the correct place, and the gray ball marks the correct color in the wrong place.

Another screen shows the final result and the total of attempts made by the student, which can be evaluated by the teacher. During the game the student can click on the "Give Up" button to restart the game. 


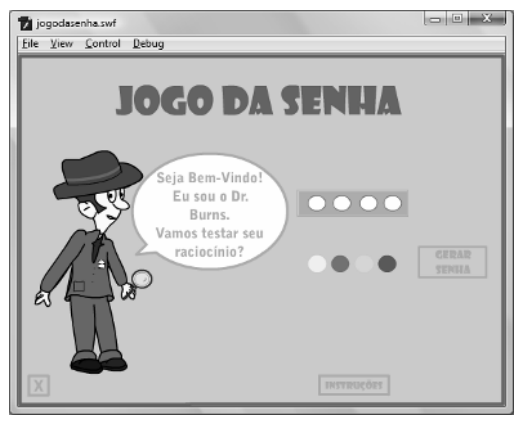

Fig. 1. Initial Screen

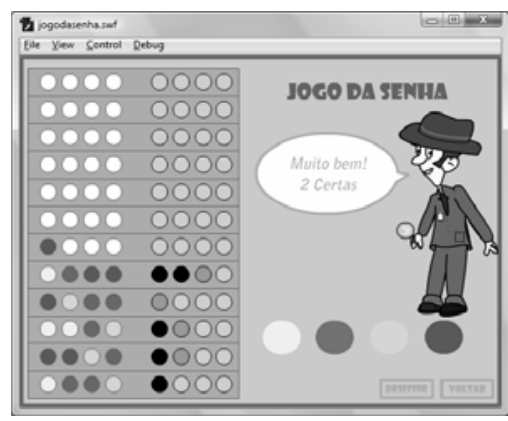

Fig. 2. Game Steps Screen

\section{4 "Math Space"}

"Math Space" explores two basic math activities, namely counting and subtraction, which are of fundamental importance in the initial years of Elementary School. The objective of the game is to perform the counting of stars that appear on the screen and, afterwards, their subtraction, which is informed through the numbers that are showed on the screen.

Figure 3 presents the initial screen of the game, where it is possible to set the number of questions to answer and to ask the agent for help. Figure 4 shows the screen of the first part of the game, where the learner must count the stars and give the correct amount by clicking on the numbers shown in the bottom part of the screen. The second part of the game shows only the remaining stars, and the student must provide the number of stars that are gone. Another screen indicates the result of correct and incorrect answers, and shows the possibility of printing the results, including the student's identification, which can be used by the teacher as an instrument of evaluation.

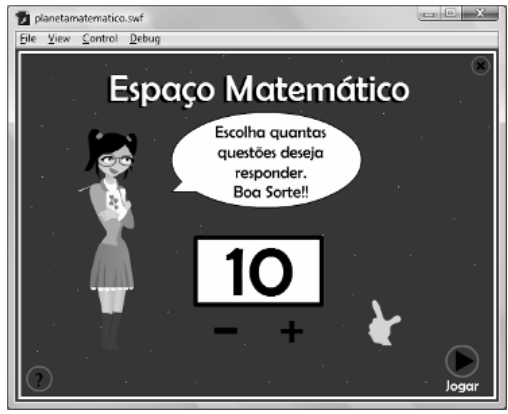

Fig. 3. Initial Screen

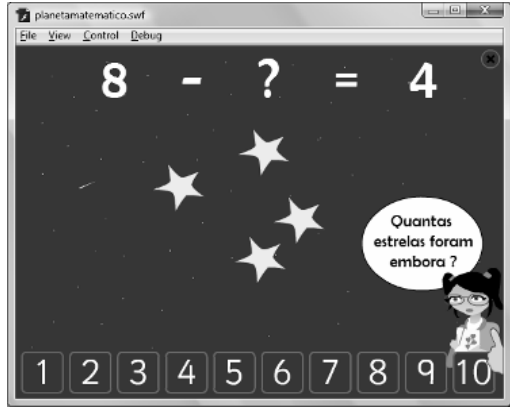

Fig. 4. Phase 1 Screen

\section{The Developed Agents}

During the building of the environment, several ideas came up for the development of the agent, and modeling provided the study with the definition of the actions. The agents are developed within the environment itself. 
Because they perform tasks for the user, these agents have basic characteristics directly associated to their capacities, depending on their functionality. The developed agents perform periodic actions, have spontaneous execution and are static, that is, they are fixed in a certain location. They possess a low level of intelligence, and perform routine tasks that are triggered by external events. They perform a set of rules and do not adapt to changes. However, they use the knowledge base to reason upon monitored events.

The tasks performed by the agents are of gopher type, that is, they are simple tasks based on suppositions with pre-established rules. The acquisition of intelligence is of a reflexive/reactive sort, based on the mapping of situations and on associated responses. Thus, the agents are of reactive type, once they behave in a stimulus/response style.

\subsection{Functions of the Agents}

The pedagogical agents were developed as a tutoring tool during the structuring of students' knowledge along their interaction with the activities of the educational software.

These agents present a set of rules that determine the actions to be performed in the teaching activities. This is the base of the strategies to be used in ludic environments (games). This way, their objective is to help and monitor learners during their interactions in the environment, and not to teach.

Each pedagogical agent presents the following functions:

1. Ability to perceive students' errors and interact with them, stimulating them to explore the activities of the environment;

2. Following of students' actions during their interaction with the system;

3. Assisting students personally, performing tasks for them;

4. Motivating students to learn.

\subsection{Architecture}

A specific way to build agents is to have their architecture as a base. According to [8], the appropriate architecture depends on perceptions, actions, objectives and also on the environment. When the state of the environment is altered, the agent performs a corresponding action to cater to the new state. This is the stimulus/response style.

The Reactive Module is responsible for changes in the state of the agent during its interaction with students. The means of interaction that provide feedback are:

- Textual: activation of messages in balloons;

- Visual: facial expressions such as thoughtful, happy and unhappy.

- The base for the agent's internal knowledge is composed by:

- Base of visual resources: formed by elements that constitute the agent's appearance, such as body, balloons and others;

- Base of information: contains information on the content of the questions;

- Base of messages: consists of the phrases used in the interaction with students.

\subsection{Visual Characteristics}

In the establishing of the agent's physical characteristics, the following ideas were considered. 
The agent should:

- Be similar to reality, having a whole body, being of feminine or masculine gender and being coherent to the style of the environment;

- Not interrupt users during their learning process;

- Interact with users, subtly changing their posture and face according to situations and actions;

- Use text balloons with phrases to communicate with users.

Besides the behavioral ideas presented above, the characters "Dr. Burns" and "Nani" were devised with friendly characteristics and with young features to get and keep users' attention. They should look like cartoons, as shown in Figures 5 and 6.

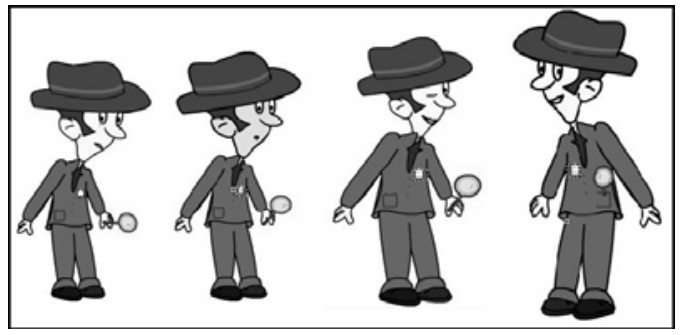

Fig. 5. Forms of Agent Dr. Burns in "Password Game"

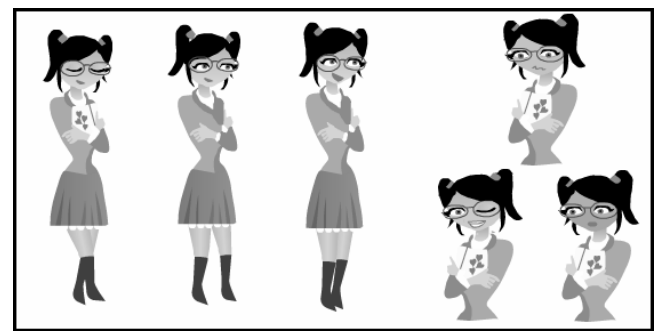

Fig. 6. Forms of Agent Nani in "Math Space"

\section{Results}

The validation of this study was done in the participating schools. As mentioned before, the study involved school students of the First and Third Grades of Elementary School.

In the test, the games were validated in six groups, with an average of fifteen students in each group. All the teachers received a new questionnaire with seven questions that evaluated the students' acceptance of the agents and their performance during the games. Some of the questions were: Do you consider the kind of game appropriate? Did the game offer improvement for the curriculum activities? Did the students show enhanced interest in learning through the game? Do you think that the 
presence of the agent brought contributions to students' interaction with the game? Did you like the agent's character?

Both the games and the agents proved to be successful and well-accepted by teachers and students.

New graphs were generated from the answers given in these questionnaires. These graphs show the feedback given by teachers on the use of the games. According to the results shown by the graphs, the games were considered adequate and they provided improvement for the curriculum activities, due to the interest and participation shown by students.

As for the objective of the pedagogical agent, it made the environment more motivating and interactive. During the validation of the study, students paid attention to the messages and the facial expressions presented by the agent and performed activities so as to "make it happy".

In the questionnaire, in the space provided for suggestions, the followed comments were written: "It's good to have a contribution to the classes. The pace is better" (teacher from Escola Municipal de Educação Fundamental Centro de Atenção Integral à Criança Luizinho De Grandi). "It's important to have different learning means as alternatives" (teacher from Escola Nossa Senhora do Horto). "It's an important work that must be continued, because it enriches the environment" (teacher from Escola Municipal de Educação Fundamental Centro de Atenção Integral à Criança Luizinho De Grandi).

This proposal was a differential in the schools that participated in the study, because some of the schools used games for leisure and as free time activities, but not for teaching.

It was also possible to verify the students' performance during the test. Some of them had difficulties to play "Password" because they could not progress in their logical reasoning at each attempt to discover the password. Some had difficulties in the subtraction phase in "Math Space" because they were not used to using computer resources that demanded greater need of concentration and reasoning.

\section{Closing Thoughts}

The emergence of educational technologies has allowed for changes in the pedagogical paradigm. Teachers have been opening doors for the use of resources that go beyond traditional teaching-learning methods. Thus, educational games are tools that complement the building and the consolidation of concepts to which students are exposed in the classroom.

The development of this study considered the phases of definition and modeling of the games "Password" and "Math Space", the development of the environment and the creation of the animated character that represent the agent that is embedded in the environment.

The final phase of the study was the validation of these games in the teaching environment of the schools that participated in the definition of the model of the games. The validation consisted in checking the benefits that the games provided and the inclusion of the agent, considering that the use of agents in educational games is not common. 
It was possible to conclude that the introduction of computer technology in education is a rich tool that can be used as a new form of learning, as a novel pedagogical instrument that has much to contribute to students' building of knowledge.

This work contributes to a series of other studies about the use of computers in the classroom and its potentialities. Another point that is worth mentioning is the use of a pedagogical proposal to determine the activities and the work that the teacher can perform with the results that are obtained from students' interaction with the software.

\section{References}

1. Tarouco, L.M.R., Roland, L.C., Fabre, M.C.J.M., Konrath, M.L.P.: Jogos Educacionais, CINTED Novas Tecnologias na Educação, UFRGS, Porto Alegre (2004)

2. Botelho, L. Jogos educacionais aplicados ao e-learning (2003), http: / /www.elearningbrasil.com.br/news/artigos/artigo_48.asp (January 10 2008)

3. Santos, C.T., et al.: DORIS: Um agente de acompanhamento pedagógico em sistemas tutores inteligentes, In: Simpósio Brasileiro de Informática na Educação, Anais, Vitória/ES (2001)

4. Gardner, H.: Estruturas da Mente. A Teoria das Inteligências Múltiplas. Artes Médicas Sul, Porto Alegre (1994)

5. Zacharias, V.L.C.F.: Jogo e Ed. Infantil (2007), http: / /www. centrorefeducacional.com.br/jogomais.htm (accessed October 18, 2007)

6. Fernandes, A.M.R.: Inteligência Artificial: noções gerais, 1st edn., cap. 1 and cap. 5. Sarvier, São Paulo (2003)

7. Pereira, A.S.: Um agente para Seleção de Estratégicas de Ensino em Ambientes Educacionais na Internet. In: Dissertação de Mestrado, p. 82. PPGCC da UFRGS, Porto Alegre (1999)

8. Russell, S., Norvig, P.: Inteligência Artificial, 2nd edn., cap. 2. Campus, São Paulo (2004) 